\title{
Presenting symptoms of autism in Sri Lanka: analysis of a clinical cohort
}

\author{
Hemamali Perera $^{1,2}$, Kamal Chandima Jeewandara ${ }^{3}$, Chandima Guruge ${ }^{2}$, Sudarshi Seneviratne ${ }^{1,2}$ \\ Sri Lanka Journal of Child Health, 2013; 42(3): 139-143
}

(Key words: autism; children; diagnosis; presenting symptoms; speech/language delay)

\begin{abstract}
Introduction: Diagnosis of autism is based on the presence of social interactional and communication impairment and certain behavioural characteristics. Most documented accounts on symptom profiles in autism come from developed countries and studies on ethnically different populations are few, although this knowledge is crucial to screening and early recognition. Common presentation of autism in Sri Lanka has not been identified.
\end{abstract}

Method: The data for this descriptive study was obtained from an existing computerised data-base of a clinical cohort of children diagnosed with autism. Diagnosis was made on prospective data gathered from: (i) parental report on development and behaviour and (ii) direct observational assessment of social interaction and communication, quality of play and abnormal patterns of behaviour. Final diagnosis of autism was made on fulfillment of DSM IV-TR diagnostic criteria.

Results: Data on 244 children was analysed. Mean age was 35.8 months (SD 12.44, median 35.8, mode 30 months, range 13 to 96 months). Average age of diagnosis of the sample was 35.8 months. $48.2 \%$ presented at 25-36 months of age. The majority (77.4\%) were male. Poor development of speech for age was the primary concern of parents in $82.3 \%$. Hyperactivity, abnormal play behaviour, and social un-connectedness were reported as presenting problems only in $4.9 \%, 1.2 \%$ and $1.2 \%$ respectively. On assessment, the presence of a range of behavioural problems (14.6\%), stereotyped behaviours $(24.3 \%)$ and regression of speech $(47.3 \%)$ was elicited. Co-occurring physical disorders were present in $18.8 \%$ with $10.6 \%$ having a seizure disorder. Atypical autism was diagnosed in $20.8 \%$.

${ }^{1}$ Faculty of Medicine, University of Colombo, ${ }^{2}$ Lady Ridgeway Hospital for Children, Colombo, ${ }^{3}$ Faculty of Medical Sciences, University of Sri Jayewardenepura

(Received on 11 March 2013: Accepted after revision on 19 April 2013)
There was no statistically significant association between age of presentation and type of presenting problem or associated disorders ( $p>0.05)$.

Conclusions: Poor development of speech was the primary concern of parents to seek medical help irrespective of age. The rate of recognizing social impairment and other main characteristics of autism was low.

\section{Introduction}

Autism is a neuro-developmental disorder with the characteristic features of qualitative impairment of social interaction and social communication, restricted interests, repetitive behaviours and mannerisms ${ }^{1,2}$. The assessment of autism should focus on the specific developmental deficits, identification of the comorbid conditions and exclusion of other developmental disorders. This process could be complicated by widely varying intensity of symptoms in a clinical population and cooccurring behavioural and physical disorders. Laboratory tests, culturally validated standardized diagnostic tools, or specific structural and functional markers are not available in autism. Hence, the diagnosis relies heavily on social behavioural criteria that are identified from information provided by caregivers and clinical observation. It is now accepted that the diagnosis of autism can be reliably made by the age of 2 years, and behaviour predictive of autism is evident as early as 12 or 18 months $s^{3-6}$.

Most documented accounts on presentations and symptom profiles of autism come from Western countries. Research on ethnically diverse populations though few, has shown wide variations in presentation and parent opinion about them ${ }^{7}$. A study in the United States showed that ethnic-minority children, with autism when compared to those from ethnic-majority, had lower scores on measures of language, communication and gross motor skills. Also, ethnic-minority mothers paid less regard for subtle language delay and reached services later than the ethnic majority ${ }^{8}$. However, ethnic or racial differences in core autism symptoms have not been identified $^{9}$. Nevertheless, significant ethnic and 
cultural differences have been documented in all associated behavioural problems in autism, especially challenging behaviours ${ }^{10}$.

The common modes of presentations of autism in Sri Lanka are not known, despite recognition of high community prevalence ${ }^{11}$. This knowledge is important for early recognition of autism in clinical and community groups as it will provide opportunity for early intervention. This paper describes the profile of symptoms at the first presentation in a cohort of children with autism.

\section{Method}

The data for this descriptive study was obtained from an existing computerised data-base of a clinical cohort of children diagnosed with autism and attending an intervention programme. The diagnosis of autism was made on the data gathered from different sources at the time of entry into the programme. These were: (i) screening for autism using a self-assessment tool (sensitivity 88\%, specificity $93.3 \%$; positive predictive value $95.2 \%$, negative predictive value $84 \%)^{12}$ completed by the parents, (ii) parental report of their concerns about the child's early and current development and behaviour, which was recorded on a semi-structured format, and (iii) direct observational clinical assessment of social interactional, social communication, quality of play and presence of abnormal patterns of behaviour. A final diagnosis of autism was made on the fulfillment of DSM IV-TR ${ }^{2}$ diagnostic criteria. Children who were already diagnosed on entry into the intervention programme were excluded ( 4 children) from this sample to avoid contamination from acquired knowledge in parents. Frequency distribution and Chi Square Test were used to analyse data and estimate the association between variables. Ethical clearance was obtained from Faculty of Medicine, University of Colombo and Lady Ridgeway Hospital for Children. The autism intervention programme is registered with Sri Lanka Clinical Trials Registry.

\section{Results}

The sample analysed consisted of 244 children with the mean age of 35.8 months (SD 12.44, median 35.8 months, mode 30 months and range 13 to 96 months). As none of the children had a previous diagnosis of autism at the time of first contact with the intervention programme, the average age of diagnosis of the sample was also considered as 35.8 months. Table 1 gives the frequency distribution of age at diagnosis. The majority, $188(77.4 \%)$ were male. Ethnic distribution was 231 (94.7\%) Sinhalese and the rest were from Tamil, Muslim and Malay populations.

Table 1: Distribution of age of diagnosis of autism

\begin{tabular}{|c|c|}
\multicolumn{2}{|c|}{$(\boldsymbol{N}=\mathbf{2 4 4})$} \\
\hline Age of Diagnosis & No, (\%) \\
$0-12$ months & 0 \\
$25-24$ months & $35(14.3)$ \\
$37-48$ months & $118(48.4)$ \\
$49-60$ months & $62(25.4)$ \\
Over 60 months & $18(07.4)$ \\
\hline
\end{tabular}

Majority of children, 175 (71.2\%) were self-referrals by parents. Other sources of referral were paediatrician $43(17.7 \%)$, speech and language therapists 24 (9.7\%), and ENT surgeons 2 (0.8\%). Primary carers of children in the sample were 235 fathers and 239 mothers. Their age distribution and educational achievement are given in Table 2.

Table 2: Age distribution, educational achievement and employment status of parents

\begin{tabular}{|l|c|c|}
\hline \multicolumn{1}{|c|}{ Variable } & $\begin{array}{c}\text { Fathers } \\
\mathbf{n = 2 3 5}\end{array}$ & $\begin{array}{c}\text { Mothers } \\
\mathbf{n = 2 3 9}\end{array}$ \\
\hline Mean age years (SD) & $37.1(4.73)$ & $33.0(5.00)$ \\
Age range (years) & $25-47$ & $23-44$ \\
Educational & & \\
\hline achievement & & \\
Tertiary education & $133(56.4 \%)$ & $123(51.6 \%)$ \\
Secondary education & $95(40.4 \%)$ & $108(45.1 \%)$ \\
Primary education & $7(3.2 \%)$ & $8(3.2 \%)$ \\
Occupation & & \\
Professional & $64(27.2 \%)$ & $65(27.2 \%)$ \\
Skilled & $114(48.5 \%)$ & $46(19.2 \%)$ \\
Semi-skilled & $57(24.3 \%)$ & $11(4.6 \%)$ \\
Un-skilled & $0(0 \%)$ & $2(0.84 \%)$ \\
Housewife & --- & $115(48.1 \%)$ \\
\hline
\end{tabular}

An extended family member was the main carer for 5 children and 4 were cared for by single mothers. Five mothers had left jobs to look after the child and identified as housewives. None of the fathers were reported to be unemployed. Multiple regression analysis did not show a statistically significant association between the age of first diagnosis of autism and the age of mother, age of father, educational level of mother, educational level of father, occupation of mother or occupation of father $(\mathrm{p}>0.5)$. Table 3 gives the single main area of concern the parents expressed as the reason for seeking medical consultation. Primary concerns under "Other" were - restricted food intake and food preferences, sleep disturbance, self-injurious behaviour such as self-biting and head banging. 
Table 3: Frequency distribution of single main area of concern for parents about development and behaviour of the child $(N=244)$

\begin{tabular}{|l|c|}
\hline \multicolumn{1}{|c|}{ Main area of concern for parents } & No. (\%) \\
\hline Poor development of speech for age (no speech, few words only) & $201(82.4 \%)$ \\
Regression of speech & $15(6.1 \%)$ \\
General behaviour problems (hyperactivity, temper tantrums) & $11(4.5 \%)$ \\
Social un-connectedness (poor eye contact, ignore when called, solitary play) & $3(1.2 \%)$ \\
Repetitive behaviours (in play or as stereotyped behaviours and rituals) & $3(1.2 \%)$ \\
Other & $11(4.5 \%)$ \\
\hline
\end{tabular}

Table 4 gives the distribution of co-occurring developmental and behavioural problems elicited on clinical assessment. In $23(9.4 \%)$, parents did not report any delay in speech development. The "Other" features (Table 4) included irregular sleep patterns and fearfulness about a range of situations and objects, rigid preference for particular clothing, biting and hitting self, intolerance to noise and intolerance to physical contact with other persons including parents.

Table 4: Distribution of developmental and behavioural features elicited on clinical assessment in the total sample of 244 children

\begin{tabular}{|l|c|}
\hline \multicolumn{1}{|c|}{ Symptom / Behaviour } & N (\%) \\
\hline Delay in development of speech/language skills for age (no speech, few words, jargon use, & $235(96.3)$ \\
echolalia) & $113(47.3)$ \\
Regression of speech / language & $232(95.1)$ \\
Social un-connectedness (poor eye contact, joint attention deficit, solitary play ) & $192(78.7)$ \\
Repetitive behaviours (in play and / or stereotypes and/or rituals) & $105(43.0)$ \\
Behaviour problems (temper tantrums, hyperactivity, head banging) & $47(19.3)$ \\
Restricted food preferences & $81(33.2)$ \\
Other & \\
\hline
\end{tabular}

Physical disorders were reported by parents in 46 $(18.8 \%)$, which included allergy to certain foods and medications (mainly antibiotics) in $11(4.5 \%)$, seizure disorders in $26(10.6 \%)$, bronchial asthma in $6(2.5 \%)$ and gastro-intestinal symptoms in $3(1.2 \%)$. The majority $193(79.2 \%)$ fulfilled diagnostic criteria for typical autism and atypical autism was diagnosed in $51(20.8 \%)$. Two children were diagnosed with autism related genetic disorder of Fragile $\mathrm{X}$ syndrome and one with tuberous sclerosis. Statistically significant association was not found between age of presentation and the presenting problem, or any associated physical or behavioural disorders $(\mathrm{p}>0.05)$.

\section{Discussion}

In our cohort, by the age of 24 months, only $14.3 \%$ of children with autism were seeking help. In comparison, similar studies in UK and US show that parents made contact with relevant services by the age of 24 months in $30 \%$, and by 24 months in $80 \%{ }^{13,14}$. A lower figure of $48.5 \%$ at 2 years has also been reported ${ }^{15}$, but still a higher rate than our finding. The presence of physical disorders in $18.8 \%$ with $10.6 \%$ being affected by seizures may have distracted some parents from seeking help for the child's development. The gender distribution of our sample of a male preponderance of $77 \%$ is in keeping with the known 3 to 4 times higher prevalence reported in boys.

Speech and language delay was the commonest concern expressed by the parents in our study (82.4\%). This finding replicates that in many similar studies with regard to the main presenting complaint in children with autism ${ }^{14-17}$. Parents did not report any speech problem in $9.4 \%$ of children. However, clinical assessment showed language dysfunctions (including delay) in $96.3 \%$. A possible explanation for this discrepancy is that parents counted jargon speech and echolalia as normal or unique language use rather than delayed development. A discrepancy was also noted with regard to speech regression between parental report $(6.5 \%)$ and findings on clinical assessment (41.9\%). Regression of language (evident around 21-21 months) is known in 25-30\% of children with autism ${ }^{13,16}$. A higher prevalence in Sri Lankan children has been identified ${ }^{18}$. Similarly, poor social connectedness was the primary concern for parents in only $1.2 \%$, whereas other studies have reported higher figures of $19.3 \%{ }^{13}$. Although missed by many Sri Lankan parents, social impairments (poor eye contact, not orienting to social stimuli, 
limited social engagement and isolation), can be reliably be recognized in toddlerhood ${ }^{17}$. However, cultural beliefs about appropriate social behaviour may prevent early recognition of such impairments by parents $^{7,8}$. Further, repetitive stereotyped behaviours were evident on assessment in over 50\% of children, but were reported as a concern by parents only in $1.2 \%$. In other studies too, low figures (3.7\%) have been reported ${ }^{13}$. A higher frequency and longer duration of repetitive behaviour is seen at 18-24 months with a reduction later ${ }^{19}$. It was worthy of note that in 5\% of children, hyperactivity and temper tantrums rather than deviant or delayed development was the main presenting complaint by parents.

Strength of this study is that it identified specific markers in the presentation of autism in Sri Lankan children in a large cohort. A shortcoming is that the sample is hospital based, and may not represent the general population. The higher socioeconomic representation of parents, where $75.7 \%$ of fathers were in professional or skilled occupations is probably the result of selective access to the intervention programme. At the same time, an interesting fact is that a national community based epidemiological study in United States reported a higher prevalence of autism in wealthier counties, but this too was explained on differential access to services $^{20}$. Other reports have failed to find a relationship between autism and socioeconomic factors $^{21}$.

\section{Relevance to clinical practice}

The study highlights that delay in speech development is a red flag sign for autism, which is useful in screening and surveillance for early recognition. However, some children may present with behaviour difficulties rather than with core symptoms of autism. Nearly 1 in 5 children have cooccurring physical disorders.

\section{References}

1. World Health Organization, International Classification of Diseases $10^{\text {th }}$ Edition. (ICD-10). WHO Geneva 1997.

2. American Psychiatric Association. Diagnostic and Statistical Manual of Mental Disorders $4^{\text {th }}$ Edition Text Review (DSM IV-TR) Washington DC 1994.
3. Charman T, Baird G. Practitioner review: diagnosis of autism in 2-3 year old children. Journal of Child Psychology and Psychiatry 2002; 43(3): 289-305.

http://dx.doi.org/10.1111/1469-7610.00022

4. Stone WI, Lee EB. Can autism be diagnosed accurately in children under three years? Journal of Child Psychology and Psychiatry 1999; 40(2): 219-26.

http://dx.doi.org/10.1111/1469-7610.00435

5. Osterling J. Dawson G. Early recognition of children with autism: a study of first birthday home video tapes. Journal of Autism and Developmental Disorders 1994; 24(3): 247-57. http://dx.doi.org/10.1007/BF02172225

6. Webb SJ, Jones EJH. Early identification of autism - early characteristics, onset of symptoms and diagnostic stability Infants \& Young Children 2009; 22(2): 100-18, http://dx.doi.org/10.1097/IYC.0b013e3181a02f7f

7. Bernier R, Mao A, Yen J. Psychopathology, families and culture: autism. Child and Adolescent Psychiatric Clinics of North America 2010; 19(4): 855-67. http://dx.doi.org/10.1016/j.chc.2010.07.005

8. Tek S, Landa RJ. Differences in autism symptoms between minority and non-minority toddlers Journal of Autism and Developmental Disorders 2012; 42(9): 1967-73.

http://dx.doi.org/10.1007/s10803-012-1445-8

9. Cuccaro ML, Brinkley J, Abramson RK, Hall A, Wright HH, Hussman JP, Gilbert JR, PericakVance MA. Autism in African American families: clinical-phenotypic findings American Journal of Medical Genetics Part B: Neuropsychiatric Genetics 2007; 144B (8): 1022-6. http://dx.doi.org/10.1002/ajmg.b.30535

10. Horovitz M, Matson JL, Rieske RD, Kozlowski AM, Sipes M. The relationship between race and challenging behaviours in infants and toddlers with autistic disorder and pervasive developmental disorder-not otherwise specified. Developmental Neurorehabilitation 2011; 14(4): 208-14. http://dx.doi.org/10.3109/17518423.2011.566596 
11. Perera H, Wijewardena $\mathrm{K}$, Aluthwelage $\mathrm{R}$. Screening of 18-24-month old children for autism in a semi-urban community in Sri Lanka. Journal of Tropical Pediatrics 2009; 55(6): 402-5. http://dx.doi.org/10.1093/tropej/fmp031

12. Perera H, Jeewandara KC, Seneviratne S. A new approach to screening for autism in preschool children in a tertiary care setting Proceedings of the Annual Academic Conference; Sri Lanka College of Paediatricians 2011.

13. De Giacomo A, Fombonne E. (1998). Parental recognition of developmental abnormalities in autism European Child \& Adolescent Psychiatry 1998; 7(3): 131-6. http://dx.doi.org/10.1007/s007870050058

14. Howlin P, \& Moore A. (1997). Diagnosis in autism. Autism 1997; 1(2): 135-62. http://dx.doi.org/10.1177/1362361397011015

15. Chawarska K, Paul R, Klin A, Hannigen S, Dichtel LE, Volkmar F. Parental recognition of developmental problems in toddlers with autism spectrum disorders. Journal of Autism and Developmental Disorders 2007; 37(1): 62-72. http://dx.doi.org/10.1007/s10803-006-0330-8

16. McConkey R., Truesdale-Kennedy M., \& Cassidy A. Mothers' recollections of early features of autism spectrum disorders. Child and Adolescent Mental Health 2008; 14(1): 31-6. http://dx.doi.org/10.1111/j.14753588.2008.00495.x
17. Baird G, Cass H, Slonims V. Diagnosis of autism. British Medical Journal 2003; 327: 48894.

http://dx.doi.org/10.1136/bmj.327.7413.488

18. Perera H, Jeewandara KC, Seneviratne S, Guruge BC. Developmental language regression in autism: A descriptive study in Sri Lanka. Sri Lanka Journal of Child Health 2012; 41(1):15-9. http://dx.doi.org/10.4038/sljch.v41i1.4132

19. Watt N, Wetherby AM, Barber A, Morgan L. Repetitive and stereotyped behaviour in children with autism spectrum disorders in second year of life. Journal of Autism and Developmental Disorders 2008; 38(8): 1518-33. http://dx.doi.org/10.1007/s10803-007-0532-8

20. Thomas P, Zahorodny W, Peng B, Kim S, Jani $\mathrm{N}$, Halperin W, Brimacombe M. The association of autism diagnosis with socioeconomic status Autism 2012; 16(2): 201-13. http://dx.doi.org/10.1177/1362361311413397

21. Croen L, Grether JK, Selvin S. Descriptive epidemiology of autism in a California population: who is at risk? Journal of Autism and Developmental Disorders 2002; 32(3): 217-24. http://dx.doi.org/10.1023/A:1015453830880 